\title{
The Effect of Non-Monetary Rewards on Employee Performance in Massive Open Online Courses
}

\author{
https://doi.org/10.3991/ijet.v15i01.11470 \\ Pradorn Sureephong $(\bowtie)$ \\ Chiang Mai University, Chiang Mai, Thailand \\ dorn@camt. info \\ Winai Dahlan \\ Chulalongkorn University, Bangkok Thailand \\ Suepphong Chernbumroong, Yootthapong Tongpaeng \\ Chiang Mai University, Chiang Mai, Thailand
}

\begin{abstract}
A challenge for organizations is to increase employee performance and motivation, since the most crucial asset of every organization is manpower. Many companies and factories have started implementing online training platforms under the concept of "Massive Open Online Courses (MOOCs)" in their workplace to foster employee performance. Previously, the mobile application called "HSC MOOC" which is provided by the Halal Science Center, Chulalongkorn University, Thailand functioned as a solution that encourages self-learning on online platforms at companies in Thailand. However, the main barrier or risk that occurs when implementing an online platform is the user's motivation, since the dropout rate is considered as a serious issue regarding MOOCs. Thus, incentive and reward were added to online training programs which aimed to motivate employees. Many types of rewards were provided for employees who had met their own company's expectations. Recently, psychology research papers have illustrated that non-monetary rewards seem to provide greater results on the side of employee's motivation. However, not all types of non-monetary rewards provide positive impact on employee's motivation. Therefore, the aim of this research is to present the effect of different nonmonetary rewards on employee performance.

Ninety volunteer employees from a food manufacturing company in Chiang Mai, Thailand participated in this research. The experiment was divided into two sections. The first section aimed to measure the motivation of employees which based on different non-monetary rewards. The questionnaire for measuring Valence, Instrumentality, and Expectancy variables (VIE theory) was deployed to test employee motivation in 3 different groups; "Tangible NonMonetary Rewards", "Social Non-Monetary Rewards" and "Job Related NonMonetary Rewards". The test consisted of 10 items using a 5-point Likert scale. The second experiment aimed to reveal which type of non-monetary reward is the most suitable for motivating employees in participating and completing the course in MOOCs. Participants in different groups were assigned to learn via MOOCs on their mobile device within a period of 30 days. Different types of non-monetary rewards were provided only for participants who had completed
\end{abstract}


certain conditions in MOOCs. The overall results showed that the group of tangible non-monetary rewards reached the significant highest score on the VIE questionnaire and over $60 \%$ of participants exposed to tangible non-monetary rewards completed the course's conditions in MOOCs.

Keywords - Employee performance, Massive open online course, VIE Theory, Non-mandatory reward.

\section{Introduction}

Nowadays, the most crucial asset of every organization is manpower since things are getting done through employees. The success or failure of an organization is heavily depending on the performance of its employees. Therefore, it is important to focus on the factors affecting the performance of the employees [1]. Performance is considered to be related to the concepts of ability, opportunity and motivation. Ability is a function of skills, education, experience and training. Opportunity refers to the infrastructure needed to perform a job. Finally, motivation is the desire to achieve a goal and willingness to exert effort for it [2]. Motivation is something that can lead to better performance when other conditions are met. Thus, all organizations, whether public or private, need motivated employees to be effective and efficient in their functioning, in addition to other factors. Employees who are motivated to work energetically and creatively toward the accomplishment of organizational goals are one of the most important inputs to organizational success. Consequently, the challenge for organizations is to ensure that their employees are highly motivated.

In Thailand, many companies and factories are currently running their training programs on online platforms. The well-known innovation, the e-learning under concept called "Massive open online course" has been playing an important role as a potential training strategy for Thai companies. The advantage of MOOCs at companies are enormous since different strategies can be adopted in order to tailor the Massive Open Online Courses paradigm to meet the company's learning and training expectations. The most prominent use-case is the fact that it can expand corporate training options [3]. This platform allows employees to improve their abilities anytime and anywhere. Previously, the mobile application called "HSC MOOC" which was provided by the Halal Science Center, Chulalongkorn University, Thailand was a solution that encouraged self-learning on online platforms for Thai companies. This application has been used by in more than 300 employees in Chiang Mai, Thailand. However, the main barrier or risk in implementing the online platform is user motivation, since the dropout rate is considered as a serious issue regarding MOOCs [4].

As regards the high dropout rate in MOOCs, the companies usually increase the motivation of their employees towards attending the online training program by offering an incentive or reward. Many types of rewords were provided for the employees who met their own company's expectations. Previously, psychology research papers illustrated that non-monetary rewards seem to provide greater results regarding employee motivation [5]. However, the literature shows that not all types of non- 
monetary rewards provide a positive impact on employee motivation [6]. Nonmonetary rewards can be classified into 3 groups; "Tangible Non-Monetary Rewards", "Social Non-Monetary Rewards" and "Job Related Non-Monetary Rewards". Although there are many concepts that explained the reasons for positive results of non-cash rewards in different aspects, what we observed is that the impact of noncash reward tends to be greater than that of cash rewards, however it also depends on how employees evaluate certain rewards according to their own expectations. Therefore, providing suitable non-monetary rewards should foster employee motivation to participate in MOOC and can decrease the dropout rate. The aim of this research is to demonstrate the effect of different non-monetary rewards on employee performance. The experiment was divided into 2 sections. In the first section, the motivation of employees was tested based on different types of non-monetary rewards by using the Valence, Instrumentality, and Expectancy (VIE) Theory. The second experiment shows which type of non-monetary reward is the most suitable for encouraging employees to complete courses in MOOCs.

\section{$2 \quad$ Literature Review}

\subsection{Psychology of monetary and non-monetary rewards}

From an economist perspective, monetary rewards are always better than any nonmonetary rewards of equal market value since cash has an option value [7]. Furthermore, it would be very difficult to know the exact preference of employees regarding non-monetary rewards. If given cash, an employee can purchase any reward offered by the company. However, previous psychology research papers illustrate that nonmonetary rewards seem to provide greater results on employee motivation. For example, the employees in 34 organizations of the U.S. ranging from Universal Studios to the U.S. Postal Service mentioned that monetary reward is not a reward, but it is a compensation. Moreover, monetary rewards usually decrease teamwork performance as employees focus primarily on individual cash gains. In contrast, non-cash incentives provide lower stress, absenteeism, and turnover and raise morale, productivity, competitiveness, revenue and profit [8]. A survey conducted by the American Express Incentive Services showed that $32 \%$ of the employees who received bonus stated that the cash incentive did not improve their work performance. At the same time, almost $70 \%$ of the employees polled, reported that non-monetary incentives provided the best motivation to improve their job performance [9]. The Malaysian retail sector survey on job satisfaction of employees also revealed that employees who gain monetary rewards may create a strong desire for money that will lead to high pay dissatisfaction in their jobs. On the other hand, non-cash incentive is a recognition separated from compensation that shows respect and commends accomplishment [10]. As far as social aspects are concerned, the average motivational impact length of payments on employees is less than two weeks. Tangible non-monetary incentives on the other hand have a long-lasting effect. [11]. 
The above research papers emphasized more the positive impacts of non-monetary reward. There are a number of psychology concepts that describe reasons why employees might exert more effort in pursuing a tangible non-monetary award than a cash bonus with the same value of that reward, even if employees state a preference for cash. Some principles of social and cognitive psychology provide reasons to believe that employees may perceive non-monetary rewards to be more valuable than the retail value of that award in cash. For example, most companies usually provide goods or services as non-cash rewards such as items which can lead to pleasurable experience rather than providing more instrumental or functional items [12]. The concept of evaluability explains that the nature of the reward triggers an affective reaction to the reward that becomes a more salient attribute than the cash value of the reward. The reason is that employees use their feelings as information when determining the value of the expected reward [13], [14]. Moreover, cognitive dissonance reductions suggest that if employees are working hard to achieve an expected award, then they will attempt to convince themselves that the award is worth a great deal to them, bringing their beliefs in line with their actions [15]. The concept of justifiability also argues that specific attributes of non-monetary rewards such as luxury or uniqueness might create an expectation in the employee. If an item is something that an employee values highly but would never purchase for him- or herself, then the opportunity to earn it as a reward for hard work provides a way to obtain the desired object without violating one's standards of justification [14]. Social reinforcement also supports that non-cash rewards are able to provide the acknowledgement of one's job performance by peers, supervisors, family, and friends. This reinforcement comes from others knowing about one's good performance rather than the receipt of a cash reward [16]. As we can see there are many concepts that explain the reasons for the positive results of non-cash rewards from different aspects. What we observed is that the value of non-cash rewards tends to be greater than cash rewards, however it also depends on how the employees evaluate the certain reward based on their own expectations. In the next session, Valence, Instrumentality, and Expectancy (VIE) Theory will be presented as the concept that we applied for explaining expectation.

\subsection{Valence, instrumentality, and expectancy (VIE) theory}

Valence, Instrumentality, and Expectancy (VIE) is a motivation theory which is resulted from Vroom's (1964) research work [17]. VIE theory mainly focused on individual motivation which usually depends on the expectation of desired rewards and the ability to perform tasks. Generally, employees are motivated to work when they have the expectancy that effort leads to performance and that performance results in reward (see Fig.1). It also assumes that individuals have different levels of satisfaction they expect to receive from rewards and each person is a rational decision maker who will expend effort on the activities that lead to their desired rewards [18]. According to the theory, the variables for measuring employee motivation is Expectancy, Instrumentality and Valence. 


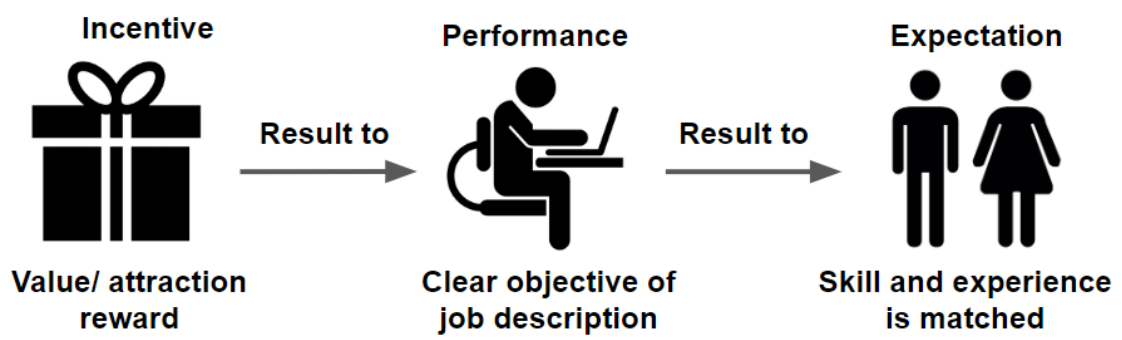

Fig. 1. Valence, Instrumentality, and Expectancy

Expectancy is "the belief that a higher or increased effort will yield better performance". This can be explained by the thinking of "If I work harder, I will make something better". There are also factors which contribute to expectancy; having the correct resources available, having the required skill set for the job at hand, and having the necessary support to get the job done correctly.

Instrumentality is "the thought that if an individual performs well, then a valued outcome will come to that individual". Some things that help instrumentality are having a clear understanding of the relationship between performance and the outcomes, having trust and respect for people who make the decisions on who gets what reward, and seeing transparency in the process of who gets what reward.

Valence means "value" and refers to beliefs about outcome desirability (Redmond, 2010). There are individual differences in the levels of value associated with any specific outcome. For instance, a bonus may not increase motivation for an employee who is motivated by formal recognition or by increased status such as promotion. Valence can be thought of as the pressure or importance that a person puts on an expected outcome.

As mentioned above, these three factors have effects on motivation but for an employee to be highly motivated, all these three factors must be high. For example, if an individual believes in his/her ability to show the required performance but do not expect that there is a reward for the outcome or do not want that particular reward, then he/she will be less likely to exert much effort. Consequently, if employees are offered non-monetary rewards that they value, they will be highly motivated to achieve the targeted outcomes. Previously, non-monetary rewards can be classified into 3 groups; "Tangible Non-Monetary Rewards", "Social Non-Monetary Rewards" and "Job Related Non-Monetary Rewards". Different groups of rewards have different purposes which can be presented in different results. Thus, the types of nonmonetary rewards will be presented in the next session.

\subsection{Types of non-monetary rewards}

Non-monetary rewards are classified as tangible rewards, social practices or jobrelated factors that are used in an organization to foster employees' motivation without direct payment of cash. It has been noted that the reward which is presented in this study is different from rewards in other areas such as gamification or game-based 
learning. The reward which is usually added to online platforms is based on the game element concept. For example, Suepphong et al. (2017) implemented leaderboard in the context of online learning to motivate learners to attend the platform. Ranking in leaderboard is perceived as a social reward when the learner performs well [19]. Added game elements in MOOCs such as points, badges, or trophy is also a popular concept that fostered learners' motivation by offering non-physical rewards [20]. In contrast, the non-monetary reward is represented as a physical object or extrinsic reward that the learner is able to redeem from the online platform. This non-monetary reward classification is a breakdown of on-the-job rewards which proposed by Meacham and Wiesen [21].

The tangible non-monetary rewards: Refer to items or services such as desk accessories, coffee mugs, clothing, gift certificates, spa passes, free food/beverage, holiday trips which are provided by the organization. These rewards provide employees tangible symbols of achievement and they become something physical to show. Tangible non-monetary incentives that are awarded as recognition of a good performance can often be shown to co-workers and friends. Offering the employees things that they value can make them feel that the organization cares about them as valuable human beings. However, implementing tangible non-monetary rewards may cause conflicts in the organization. For example, unclearly defined employee performance criteria may lead to situations that create perceived inequalities at the workplace.

Social non-monetary rewards: Are related to the relationship of people among the organization. These social rewards have an ensuring role in satisfying certain needs of employees such as social acceptance and affiliation, self-esteem and selfrealization. Examples of social rewards are a letter of commendation/ appreciation, public recognition in a meeting, newsletter, bulletin board, employee of the month award, invitations to coffee/lunch with the CEO etc. These kinds of rewards are all means of presenting that the employees are valued, cared and appreciated by their superiors.

Job-related non-monetary rewards: Are related to job-task issues that can foster employee motivation. Meaningful job tasks allow employees to use knowledge and skills with some degree of autonomy and flexibility in terms of working hours, leading to an employee being motivated to exert more effort on the job. Job-related nonmonetary rewards such as participation in decision making, growth opportunities such as training programs, promotion, international work trip opportunities, flexible working hours and time-offs are suspected to be great motivators by satisfying employees. However, there are some issues that need to be considered before implementing this kind of reward. Some employees may not be satisfied with these kinds of new job arrangements unless they are reasonably satisfied with economic well-being and affiliation. Furthermore, there may be some negative responses since new job-task promotions which offered to employees may require considerable effort, time and training process. 


\section{$3 \quad$ Field Study 1}

The aim of field study 1 is to measure the motivation of employees based on different types of non-monetary rewards by using the Valence, Instrumentality, and Expectancy (VIE) Theory.

\subsection{Item construction}

The item construction of valence, instrumentality, and expectancy in this study was adopted from [22]. The item was modified and reviewed by five experts of human resources and psychology from the Department of Humanities, Chiang Mai University. The items were edited and revised according to the feedback from these experts. Items of each variable in the VIE theory were re-designed so that the scale could be applied in a variety of employment and research settings. The outcome reference for valence (e.g. a reward in the selection context) is likely to be changed in each type of reward that offered to the employee. Valence is consisted of 3 items (e.g., "I want to get [type of reward]"). The hypothesized Instrumentality subscale contained 4 items (e.g., "I think you will get [type of reward] if you complete online courses"), Expectancy is consisted of 3 items (e.g., "If you concentrate and try hard you can complete online courses").

According to the VIE theory, we believed that offering different types of nonmonetary rewards to employees would provide different results for personal valence that may affect instrumentality, and expectancy. Thus, the item of valence and instrumentality in the questionnaire was re-designed and edited based on the types of non-monetary rewards in the three groups. Premium coffee mugs were selected as rewards in the tangible non-monetary rewards group. The letter of commendation from CEO was the selected reward in the social non-monetary reward group. And training programs were selected as rewards in the job-related non-monetary reward group. Items which were used in this research are listed in the Appendix.

\subsection{Measurement}

The participants selected the items that described their attributes in the VIE questionnaire. The test consisted of 10 items using a 5-point Likert scale ranging from 1 (strongly disagree) to 5 (strongly agree) [23]. Although it may have been useful to survey applicants before they took the test, there were organizational constraints to administering surveys both before and after this particular selection test. Rating of the 5-point Likert scale is presented in Table 1. 
Table 1. Ratings for 5-point Likert Scale

\begin{tabular}{|l|c|c|}
\hline \multicolumn{1}{|c|}{ Options } & Points & Rating \\
\hline Strongly disagree & 1 & $1.00-1.79$ \\
\hline Disagree & 2 & $1.80-2.59$ \\
\hline Neutral & 3 & $2.60-3.39$ \\
\hline Agree & 4 & $3.40-4.19$ \\
\hline Strongly Agree & 5 & $4.20-4.99$ \\
\hline
\end{tabular}

\subsection{Procedure and participants}

The questionnaires for measuring VIE variables contained 10 items in each group and were given to nianty volunteer employees from a food manufacturing company in Chiang Mai, Thailand. Questionnaires were sent to participants in three different groups (tangible non-monetary rewards group, social non-monetary reward group, and job-related non-monetary group). All participants (30 participants in each group) were told that they need to respond to all items in the questionnaire.

Table 2. Demographic data of participants

\begin{tabular}{|c|c|c|c|c|c|c|c|c|c|c|}
\hline & \multicolumn{3}{|c|}{ Tangible non-monetary } & \multicolumn{3}{|c|}{ Social non-monetary } & \multicolumn{3}{|c|}{ Job-related non-monetary } \\
\hline & & $\begin{array}{c}\text { Fre- } \\
\text { quency }\end{array}$ & Percent & $S D$ & $\begin{array}{c}\text { Fre- } \\
\text { quency }\end{array}$ & Percent & $S D$ & $\begin{array}{c}\text { Fre- } \\
\text { quency }\end{array}$ & Percent & $S D$ \\
\hline \multirow{2}{*}{ Sex } & Male & 12 & $40 \%$ & \multirow{2}{*}{0.50} & 10 & $33.3 \%$ & \multirow{2}{*}{0.48} & 14 & $46.7 \%$ & \multirow{2}{*}{0.51} \\
\hline & Female & 18 & $60 \%$ & & 20 & $66.7 \%$ & & 16 & $53.3 \%$ & \\
\hline \multirow{3}{*}{$\begin{array}{l}\text { Age } \\
\text { (year) }\end{array}$} & $20-35$ & 16 & $53.3 \%$ & \multirow{3}{*}{0.76} & 19 & $63.3 \%$ & \multirow{3}{*}{0.68} & 18 & $60 \%$ & \multirow{3}{*}{0.68} \\
\hline & $36-50$ & 9 & $30 \%$ & & 8 & $26.7 \%$ & & 9 & $30 \%$ & \\
\hline & $51-60$ & 5 & $16.7 \%$ & & 3 & $10.0 \%$ & & 3 & $10 \%$ & \\
\hline \multirow{3}{*}{$\begin{array}{l}\text { Educa- } \\
\text { tion }\end{array}$} & $\begin{array}{c}\text { High } \\
\text { School }\end{array}$ & 9 & $30 \%$ & 0.47 & 7 & $23.3 \%$ & 0.48 & 12 & $40 \%$ & 0.50 \\
\hline & $\begin{array}{c}\text { Bache- } \\
\text { lor }\end{array}$ & 21 & $70 \%$ & & 22 & $73.4 \%$ & & 18 & $60 \%$ & \\
\hline & Master & 0 & $0 \%$ & & 1 & $3.3 \%$ & & 0 & $0 \%$ & \\
\hline \multirow{3}{*}{$\begin{array}{l}\text { Work } \\
\text { Experi- } \\
\text { ence } \\
\text { (year) }\end{array}$} & $0-3$ & 21 & $70 \%$ & 0.61 & 18 & $60 \%$ & 0.68 & 20 & $66.6 \%$ & 0.78 \\
\hline & $4-10$ & 7 & $23.3 \%$ & & 9 & $30 \%$ & & 5 & $16.7 \%$ & \\
\hline & $\begin{array}{c}\text { Above } \\
10\end{array}$ & 2 & $6.7 \%$ & & 3 & $10 \%$ & & 5 & $16.7 \%$ & \\
\hline
\end{tabular}

According to the demographic data of participants in Table 2, the average age of majority participants in all groups were 20-35 years old. (The share of participants ages $20-35$ was $53.3 \%$ in the Tangible group, $63.3 \%$ in Social, and $60 \%$ in the Jobrelated group.) The educational background of most participants was holed bachelor and high school degree. The average work experience of all participants was only 0-3 years. 


\section{$4 \quad$ Results and Discussion}

Table 3. Results of the VIE questionnaire

\begin{tabular}{|c|l|l|l|l|l|c|}
\hline & \multicolumn{2}{|c|}{ Tangible non-monetary reward } & \multicolumn{2}{c|}{$\begin{array}{c}\text { Social non-monetary } \\
\text { reward }\end{array}$} & \multicolumn{2}{c|}{$\begin{array}{c}\text { Job-related non- } \\
\text { monetary reward }\end{array}$} \\
\hline & \multicolumn{1}{|c|}{ Respond } & Mean & Respond & Mean & Respond & Mean \\
\hline V1 & Strongly Agree & 4.39 & Agree & 3.51 & Neutral & 3.01 \\
\hline V2 & Strongly Agree & 4.26 & Agree & 3.45 & Agree & 3.52 \\
\hline V3 & Strongly Agree & 4.42 & Agree & 3.66 & Neutral & 3.15 \\
\hline I1 & Agree & 3.80 & Agree & 3.57 & Agree & 3.62 \\
\hline I2 & Strongly Agree & 4.33 & Agree & 3.89 & Agree & 3.70 \\
\hline I3 & Strongly Agree & 4.29 & Neutral & 3.24 & Agree & 3.67 \\
\hline I4 & Agree & 3.54 & Agree & 3.74 & Neutral & 3.15 \\
\hline E1 & Agree & 3.61 & Agree & 3.95 & Agree & 3.51 \\
\hline E2 & Strongly Agree & 4.38 & Neutral & 3.31 & Neutral & 3.09 \\
\hline E3 & Agree & 3.43 & Agree & 3.71 & Agree & 3.49 \\
\hline
\end{tabular}

Table 4. The overall results of the VIE questionnaire

\begin{tabular}{|l|c|c|c|}
\hline & \multicolumn{3}{|c|}{ Average (Mean) } \\
\hline & $\begin{array}{c}\text { Tangible non- } \\
\text { monetary reward }\end{array}$ & $\begin{array}{c}\text { Social non-monetary } \\
\text { reward }\end{array}$ & $\begin{array}{c}\text { Job-related non-monetary } \\
\text { reward }\end{array}$ \\
\hline Valence & 4.35 & 3.54 & 3.22 \\
\hline Instrumentality & 3.99 & 3.61 & 3.53 \\
\hline Expectancy & 3.6 & 3.51 & 3.36 \\
\hline
\end{tabular}

According to the demographic data analysis and determination of raw test scores (Table 3 and Table 4), the considerations of Vroom's Expectancy Theory were evaluated. In order to examine the consideration of Valence, the responses obtained from the first three questions (V1, V2, V3) of the survey instrument were utilized. Since Valence deals with the value of different non-monetary rewards, these three questions essentially focused on the same question with a modification in the wording regarding obtaining the rewards. The average score of valences indicated that the participants in the tangible non-monetary group are significantly different from the participants of the social and job-related groups. The participants in the tangible group reached the highest score $(\mathrm{m}=4.35)$ while the scores of the participants of the social group $(\mathrm{m}=3.54)$ and the job-related non-monetary reward group $(\mathrm{m}=3.22)$ didn't differ significantly. These responds suggest that the participants selected the tangible as the most valuable reward. The second consideration is instrumentality. This consideration was evaluated by utilizing the scores of the four questions (I1, I2. I3. I4) of the survey that were also developed to measure this consideration. In measuring Instrumentality, these four questions used different words to assess similar thoughts related to the performance of participants. The average scores from the tangible $(\mathrm{m}=3.99)$, social $(\mathrm{m}=3.61)$, and job-related $(\mathrm{m}=3.53)$ reward groups show that there is significant difference in result among the non-monetary reward groups. Expectancy is the third consideration. Three questions (E1, E2, E3) on the survey were utilized to obtain this score. The three questions essentially asked the same thing three times, but the wording has been modified to assess the individual's expectation which is related to the performance. There is no significant difference in the average scores of expectancies 
among the groups (tangible $=3.6$, social $=3.51$, and job-related $=3.36$ ). In summary, we can see that, the average scores of instrumentality and expectancy of the participants in all three groups are not significantly different. Only participants of the tangible group reached a slightly higher score on valence than the other two groups. This means that for the participants in the tangible group the tangible reward represents a higher value. Therefore, we believe that the participants in the tangible non-monetary reward group seem to have greater motivation which might encourage participant in this group to get better success rate in MOOCs.

\section{$5 \quad$ Field Study 2}

The second field study was done with the same group of participants studied in field study 1 . The participants were volunteer employees of the same organization. The purpose of this study is to test the effect of different non-monetary rewards which were assumed to motivate employees to use MOOC in their organizations. Therefore, ninety participants were assigned to enroll the online curriculum via video lectures in a mobile application called "HSC MOOC".

\subsection{Material}

The video lecture in this curriculum consists of instructor guided and PowerPoint lessons on the topic "Introduction to Halal Food". The presentations in the videos included pictures, diagrams and the voiceover of the lecturer via PowerPoint with a total duration of 5-8 minutes per video clip. The total length of this curriculum is 180 minutes (54 video clips). A multiple-choice exercise was provided at the end of each video clip. All participants had to complete the full multiple-choice test. The total score for the multiple choices exercise was 1,500 points (10 points per question).

HSC MOOC is an online platform under the concept of massive open online course which was created by the Halal Science Center, Chulalongkorn University, Thailand aiming at unlimited participation and open access via the mobile application. This platform provides an interactive course with user forums to support learning communities among students, adult learners, professors, field experts, and the instructor. The platform is also compatible with basic digital content such as VDO, audio, pictures, online documents, and XML files, including immediate feedback to assignments such as quick quizzes or multiple-choices. This mobile application is also available on both iOS and Android (see Fig. 2). 

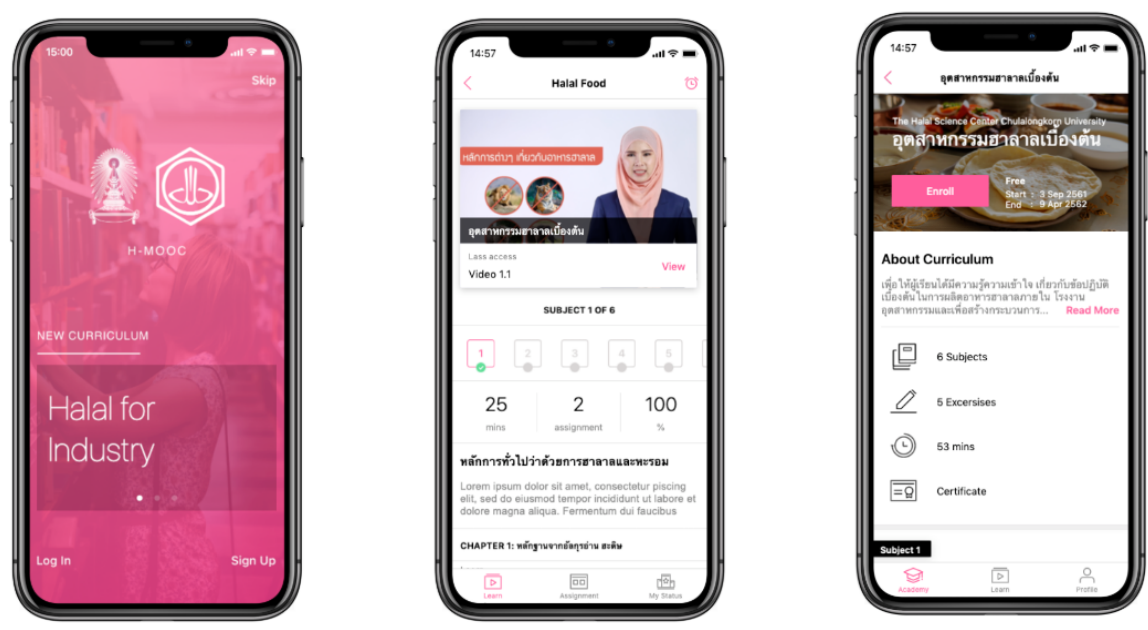

Fig. 2. Example of HSC MOOC mobile application

\subsection{Procedure and participants}

The participants from the same group of field study 1 (ninety employees) were separated into three groups (thirty participants per group) according to the types of non-monetary rewards. The participants in all groups were assigned to enroll and complete all lessons of the online curriculum. In order to complete the curriculum, participants must have fulfilled the requirement by watching all video clips and achieving a result of at least $70 \%$ on the exercise. Only participants fulfilling these requirements in MOOC were able to redeem the non-monetary rewards which were different in each group. Premium coffee mugs were provided for participants in the tangible non-monetary rewards group. In the social non-monetary reward group, the reward was a letter of commendation from the CEO. In the job-related non-monetary reward group, the reward was a training program. Participants had to complete the curriculum within 30 days. They were allowed to learn from own mobile devices, at their workplace or home, in their own preferred time frames. There was no punishment for participants who were not able to complete the curriculum (see Fig. 3). 


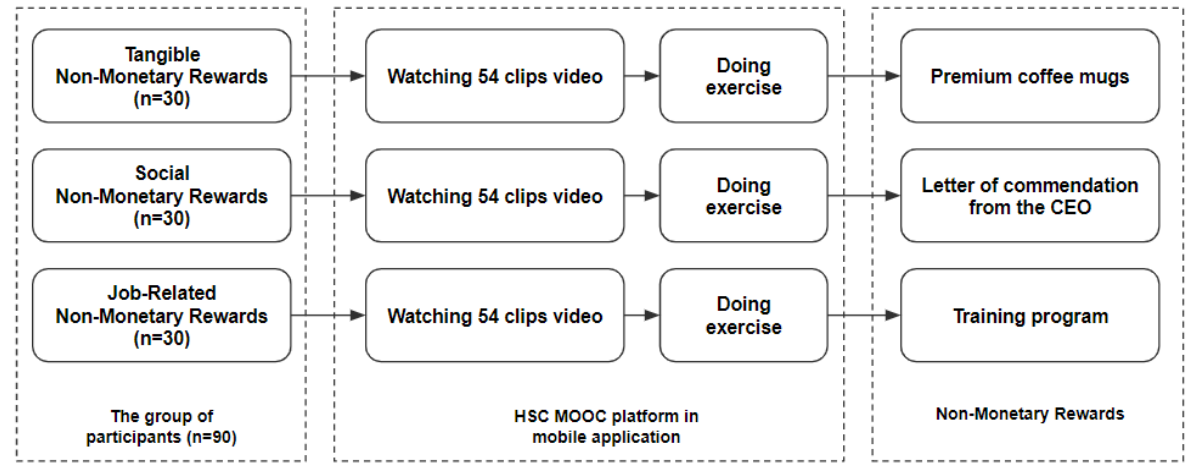

Fig. 3. Research methodology of field study 2

\subsection{Result and Discussion}

Table 5. The result from HSC MOOC participation

\begin{tabular}{|l|c|c|c|c|c|c|}
\hline & \multicolumn{2}{|c|}{ Enrollment in MOOC } & \multicolumn{2}{c|}{$\begin{array}{c}\text { Completed watching } \\
\text { 54 video clips }\end{array}$} & \multicolumn{2}{c|}{$\begin{array}{c}\text { Achieved 50\% score in } \\
\text { exercise }\end{array}$} \\
\hline & frequency & percent & frequency & percent & frequency & percent \\
\hline Tangible & 30 & $100 \%$ & 25 & $83 \%$ & 19 & $63 \%$ \\
\hline Social & 30 & $100 \%$ & 11 & $36 \%$ & 7 & $23 \%$ \\
\hline Job-related & 30 & $100 \%$ & 10 & $33 \%$ & 5 & $16 \%$ \\
\hline
\end{tabular}

According to the results, all volunteer participants (100\%) in all groups enrolled in MOOCs at the beginning of the study. The mobile application "HSC MOOC" worked smoothly and without any bugs and there weren't any problems reported by the participants. They were able to use all the features in the app, including all videos and exercises. As mentioned in the methodology section, the participants had 30 days to complete all the sessions in MOOC. At the end of the session, we found that the number of participants decreased differently in different groups. Less than half of participants in the social $(36 \%)$ and job-related non-monetary rewards (33\%) groups completed watching the video clips in MOOC. Moreover, only 7 participants $(23 \%)$ of the social group and 5 participants (16\%) in the job-related group achieved $50 \%$ on the exercise as regards scores. In contrast, more than twenty participants of the tangible reward group completed watching all the video clips. Only 11 participants $(36 \%)$ in this group failed achieve $50 \%$ on the exercise. In conclusion, there was a high dropout rate in the social and job-related non-monetary reward group since less than half of the participants completed the required conditions in MOOCs. At the same time, 19 participants from the tangible reward group fulfilled the requirements and redeemed the rewards in MOOCs.

Obviously, the participants in the tangible non-monetary reward group achieved the greatest result in MOOC which means that the reward provides a positive effect on the participants' learning motivation. The employees in the organization tended to evaluate tangible rewards as the most valuable. We can conclude that our result is consistent with the theories emphasizing the advantages of tangible rewards. Accord- 
ing to the literature, the employee justifies the physical reward as the symbol of achievement that they are able to use in their daily life. Tangible non-monetary incentives can easily be represented by employees as recognitions of good performance which can also be shown to others. Thus, we recommend that organizations select rewards that belong to the tangible category. It is worth mentioning that there was no conflict regarding the rewards when the experiment was conducted since the value of physical rewards in this experiment was not too high. We also suggest that the company should consider the cost of tangible reward provided for the employee since it could be the source of conflicts at the workplace. Furthermore, social non-monetary rewards seemed to provide negative motivation to employees. In Thailand, social and economic considerations are critical issues for the employees in the organizations. The first priority for employees is generally the income. This is why most of them tend to select rewards with a well-defined or high value than cash. A letter of commendation from the CEO is something which is beyond their expectations [12]. As far as job-related non-monetary rewards are concerned, we observed that employees usually realized that the training programs provided for them were something that had already existed at their workplace. Thus, they might not consider the job-related programs as extra rewards. In summary, we recommend that the reward that is used in organizations for motivating employees to participate in MOOC is a tangible, physical object with a well-defined price. Moreover, the reward type should not be related to their job since employees might not consider it as a reward.

\section{Conclusion}

This study described and illustrated the effect of different non-monetary rewards (tangible, social, and job-related) on employee performance. Ninety volunteer employees from a food manufacturing company in Chiang Mai, Thailand participated in this study. The experiment was conducted in two field studies to test employee motivation and performance. In filed study 1, a questionnaire for measuring Valence, Instrumentality, and Expectancy variables has been deployed to test employee motivation in 3 different groups of non-monetary rewards. The results indicated that the group of tangible non-monetary reward reached the highest score on valence variable. Employees tended to evaluate the physical objects as the most valuable rewards as opposed to social and job-related rewards. Thus, researchers believe that the participants in the group of tangible non-monetary rewards tend to have high motivation in attending the online training program. In filed study 2, the same group of participants like in field study 1 were divided in 3 different groups of non-monetary rewards and were assigned to enroll the online curriculum in "HSC MOOC". Only those participants who fulfilled the requirements in MOOCs received rewards which were different in the various groups. The result indicated that almost $63 \%$ of the participants in the group of tangible non-monetary reward completed the curriculum in MOOC. Researchers suggest that tangible reward provides a positive effect on participants' learning performance. 


\section{$7 \quad$ Acknowledgement}

Without the great support from Halal Science Center, Chulalongkorn University, Thailand, this study would never be successful. The author would like to give thanks to the Knowledge and Innovation Research Laboratory (KIRLY), College of Arts, Media and Technology, Chiang Mai University, Thailand which always provided all the facilities while conducting the research. Moreover, I would like to give thanks to all employees who voluntarily participated in the experiment.

\section{References}

[1] Okoye, P.V.C and Ezejiofor, R.A. 2013. The Effect of Human Resources Development on Organizational Productivity. International Journal of Academic Research in Business and Social Sciences. Vol. 3, No. 10 ISSN: 2222-6990. https://doi.org/10.60 07/IJARBSS/v3-i10/295

[2] Matteson, M. T., \& Ivancevich, J. M. (1987). The Jossey-Bass management series, the Jossey-Bass health series, and the Jossey-Bass social and behavioral science series. Controlling work stress: Effective human resource and management strategies. San Francisco, CA, US: Jossey-Bass.

[3] Dodson, M. N., Kitburi, K., Berge, Z. L. 2015. Possibilities for MOOCs in Corporate Training and Development. In Performance Improvement, 14-20.https://doi.org/10. 1002/pfi. 21532

[4] Onah, Daniel F. O., Sinclair, Jane and Boyatt, Russell (2014) Dropout rates of massive open online courses: behavioural patterns. In: 6th International Conference on Education and New Learning Technologies, Barcelona, Spain, and 7-9 Jul 2014. Published in: EDULEARN14 Proceedings pp. 5825-5834. ISBN 9788461705573. ISSN 2340-1117.

[5] Jeffrey, S. (2004). The benefits of tangible non-monetary incentives. Working paper, Graduate School of Business, University of Chicago.

[6] Yavuz, N., 2004, 'The use of non-monetary incentives as a motivation tool: A survey study in a public organization in Turkey', Master's thesis, Middle East Technical University, Political Science and Public Administration Dept., Ankara

[7] Waldfogel, J. 1993. The deadweight loss of Christmas. American Economic Review, 83:1328- 1336.

[8] Nelson, B. (2001). Dump the Cash, Load on the Praise. Harcourt College. [Online]. Available: http://www.fed.org/onlinemag/dec96/motiv.html 3 January 2003.

[9] American Express Incentive Services. (2003). Non-cash corner. [Online]. Available: http://www.aeis.com/Non_Cash_Corner.html. March 30, 2003.

[10] Tang, T. L. P., Luna-Arocas, R., \& Sutarso, T. (2005). From Income to Pay Satisfaction: The Love of Money and Pay Equity Comparison as Mediators and Culture (The US and Spain) and Gender as Moderators. Management Research: The Journal of the Iberoamerican Academy of Management, 3(1), 7-26. https://doi.org/10.1108/15365430580001311

[11] Jeffrey, S. A. (2002). The benefits of tangible non-monetary incentives. University of Chicago. November 4, 2002. https://doi.org/10.1037/e617892011-015

[12] Dhar, R., \& Wertenbroch, K. 2000. Consumer choice between hedonic and utilitarian goods. Journal of Marketing Research, 37: 60-71.https://doi.org/10.1509/ jmkr.37.1.60.18718

[13] Loewenstein, G., Weber, E. U., Hsee, C. K., \& Welch, E. S. 2001. Risk as feelings. Psychological Bulletin, 127: 267-286. https://doi.org/10.1037//0033-2909.127.2.267 
[14] Hsee, C. K. 1996b. Elastic justification: How unjustifiable factors influence judgments. Organizational Behavior and Human Decision Processes, 66: 122-129. https://doi.org/10.1006/obhd.1996.0043

[15] Bem, D. J. 1967. Self-perception: An alternative interpretation of cognitive dissonance phenomena. Psychological Review, 74: 183-200. https://doi.org/10.1037/h0024835

[16] Luthans, F., \& Stajkovic, A. D. 2000. Provide recognition for performance improvement. In E. A. Locke (Ed.), Principles of Organizational Behavior: 166-180. Oxford, England: Blackwell.

[17] Vroom, V. H. (1964). Work and motivation. New York: Wiley. Wanous, J. P., Keen, T. L., \& Latack, J. C. (1983). Expectancy theory and occupational/organizational choices: A review and test. Organizational Behavior and Human Performance, 32, 66-86. https://doi.org/10.1016/0030-5073(83)90140-X

[18] Montana, Patrick J; Charnov, Bruce H, Management - 4th edition; (2008) - Barron's Educational Series, Inc. ISBN 978-0-7641-3931-4

[19] S. Chernbumroong, P. Sureephong and O. Muangmoon, "The effect of leaderboard in different goal-setting levels," 2017 International Conference on Digital Arts, Media and Technology (ICDAMT), Chiang Mai, 2017, pp. 230-234.https://doi.org/10.1109/ ICDAMT.2017.7904967

[20] S. Chernbumroong, P. Sureephong and Y. Tongpaeng, "The Gamification Element Selection Method," 2019 Joint International Conference on Digital Arts, Media and Technology with ECTI Northern Section Conference on Electrical, Electronics, Computer and Telecommunications Engineering (ECTI DAMT-NCON), Nan, Thailand, 2019, pp. 179-183. https://doi.org/10.1109/ECTI-NCON.2019.8692228

[21] Meacham, M. \& Wiesen, A. (1969). Changing classroom behavior: a manual for precision teaching. International Textbook Company. In: Luthans, F., \& Kreitner, R. (1975). Organizational behavior modification. Glenview, IL: Scott, Foresman \& Co.

[22] Whittington, K. D. (2015). Does motivation predict persistence and academic success? Open Journal of Nursing, 05(01), 10-16. https://doi.org/10.4236/ojn.2015.51002

[23] Likert, Rensis (1932). "A Technique for the Measurement of Attitudes". Archives of Psychology. 140: 1-55.

\section{Authors}

Pradorn Sureephong is Associate Dean for Research and Innovation Affairs at College of Arts, Media and Technology, Chiang Mai University. dorn@,camt.info

Winai Dahlan is the Founder Director of the Halal Science Center Chulalongkorn University. He is also the Head of The Lipid and Fat Science Research as well as International Graduate Program Chair in Food and Nutrition, Faculty of Allied Health Sciences, Chulalongkorn University.

Suepphong Chernbumroong is Researcher at College of Arts, Media and Technology, Chiang Mai University.

Yootthapong Tongpaeng is lecturer and researcher at College of Arts, Media and Technology, Chiang Mai University.

Article submitted 2019-08-06. Resubmitted 2019-10-28. Final acceptance 2019-09-21. Final version published as submitted by the authors. 